\title{
NORMA Y PRESTIGIO EN EL ESPAÑOL DE AMÉRICA. APUNTES PARA UNA PLANIFICACIÓN DE LA LENGUA ESPAÑOLA.
}

\author{
Francisco Moreno Fernández \\ Universidad de Alcalá de Henares
}

\section{INTRODUCCIÓN}

Estas páginas pretenden desarrollar algunas de las ideas expuestas en nuestro trabajo "Planificación lingüistica y Dialectologia" ${ }^{1}$ y proyectarlas sobre el español de América. Una planificación del español en el mundo hispánico es, hoy por hoy, una empresa difícil, dado que falta mucho por conocer de la realidad americana en sus facetas lingüistica y socio-lingüistica y de la actitud de los propios hablantes hacia la lengua y sus usos. Mal puede planificarse cuando se conoce poco lo que ha de ser planificado. Sin embargo, no ignoramos tanto que no puedan concebirse algunas pautas generales sobre qué camino podría tomar una futura planificación de la lengua española. Los planteamientos que aquí presentamos son - no pueden ser de otra formagenerales y apriorísticos.

\section{LA CONVENIENCIA DE UNA PLANIFICACIÓN LINGÜística}

La planificación lingüistica se ha concebido y practicado en situaciones en las que dos o más variedades lingüísticas están en contacto. Generalmente esas variedades tienen la categoría de lengua. Como consecuencia, los fenómenos y problemas propios de las comunidades monolingües rara vez han sido vistos como objeto de planificación. En este tipo de comunidades es fre-

1 Publicado en Lingüística Española Actual, XIII, 1991, págs. 251-268. 
cuente encontrar hablas dialectales, regionales o locales y un habla de mayor prestigio a la que podemos llamar "normativa", vinculadas a una misma lengua. En la América hispana encontramos situaciones lingüisticas en las que conviven varias lenguas y situaciones monolingües, en las que se encuentran un habla dialectal y una variedad prestigiosa, si bien esta circunstancia también puede darse en las zonas bilingües para cada una de las lenguas allí empleadas.

Es sabido que Einar Haugen, en uno de sus primeros trabajos ${ }^{2}$, habló de tres tipos de comunidades, según las situaciones de comunicación que en ellas fueran más usuales: una comunidad primaria existe cuando las diferencias lingüísticas entre los individuos son puramente idiolectales; en una comunidad lingüistica secundaria hay inteligibilidad parcial, mientras que en una comunidad lingüistica terciaria no se da inteligibilidad, por lo que se hace necesaria la presencia de intérpretes. Para Haugen, en las comunidades $\multimap$ situaciones comunicativas - primarias la planificación es superflua, puesto que no suele haber fallas de comunicación ${ }^{3}$.

Según nuestro criterio, la tipología de Haugen es algo simple, ya que, por ejemplo, la convivencia de dos lenguas difícilmente inteligibles no supone siempre la aparición de fallos comunicativos. En muchas comunidades hispánicas en las que se maneja más de una lengua, un número importante de hablantes es bilingüe, por lo que rara vez se presentan problemas de este tipo.

Haugen tiene parte de razón al afirmar que la planificación en las comunidades primarias es superflua, pero creemos que hay situaciones dentro de estas comunidades que tienen un gran interés. Por otro lado, una planificación no tiene por qué marcarse como único objetivo el de aminorar los problemas de comunicación. El mismo Haugen dice que la planificación puede hacerse para conservar la pureza de una lengua, para fomentar su hibridación con lenguas diferentes y para aumentar o restringir los recursos de un idioma ${ }^{4}$. Sería legítimo añadir a estos objetivos otros muchos, como el de elevar o limitar el status de las variedades lingüisticas, sean del tipo que sean.

En América existen comunidades y situaciones lingüísticas en las que se dan realmente problemas de comunicación, en las que el español no tiene el status más adecuado o en las que el uso de determinadas variedades y lenguas incide de manera directa en la promoción social de los hablantes.

También hay casos en los que las variedades lingüísticas que han de en-

2 "Lingüística y planificación idiomática", en P. Garvin y Y. Lastra (eds.), Antología de estudios de etnolingüística y sociolingüística, 2. ${ }^{\text {a }}$ ed., México, UNAM, 1984, pags. 278-302. Publicado originalmente con el título "Linguistics and Language Planning", en W. Bright (ed.), Sociolinguistics, La Haya, Mouton, 1966, págs. 50-71.

3 Haugen pone como ejemplo de comunidad terciaria Suiza, de comunidad secundaria el Reino Unido y de comunidad primaria Islandia. Ibíd., págs, 285-286.

4 Art. cit., pág. 281 
señarse y en las que hay que enseñar son el origen de actitudes lingüísticas conflictivas y casos de rechazo del habla utilizada en determinados medios de comunicación social, aunque la lengua del emisor y el receptor sea la misma.

Finalmente, parece claro que entre los estratos socio-culturales más bajos de las comunidades hispánicas hay un distanciamiento lingüístico (en todos los niveles), provocado por la falta de contacto con otras normas, que no se conoce entre los estratos más elevados. Por todo ello, no carece de sentido pensar en una planificación de la lengua española ${ }^{5}$. Durante mucho tiempo, las disquisiciones de los hombres de letras han estado centradas en defender o ignorar el purismo en los usos lingüísticos ${ }^{6}$, pero estamos en condiciones de ir al terreno de lo práctico y de plantear nuevos problemas.

El mundo hispánico tiene una conciencia de colectividad lingüística y cultural que facilitaría mucho la labor de los planificadores. Además hay que tener en cuenta que América no desconoce el fenómeno de la planificación, ni del corpus ni del status, como tampoco ha sido ajena, a lo largo de su historia, al ejercicio de la política lingüistica ${ }^{7}$. La planificación del español se realizaría en las mejores condiciones si los hispanohablantes llegaran a un acuerdo, con sentido común ${ }^{8}$, sobre sus objetivos generales.

5 Al menos se ha planteado el tema en algunos trabajos. Véanse E. Chang-Rodríguez, "Problems for Language Planning in Perú", Word, XXXIII, 1982, págs. 173192; Fundamentos lingüisticos para una política idiomática en la comunidad hispanohablante, Santiago de Chile, Universidad de Chile, 1985; H. Obregón Muñoz, Hacia la planificación del español de Venezuela y la determinación de una política lingüística, Caracas, Instituto Universitario Pedagógico de Caracas, 1983; S. Brice Heath, La política del lenguaje en México, México, Instituto Nacional Indigenista, 1972; E. Fernández Arévalos, "Presupuestos para una política lingüística en el Paraguay", Caravelle, XIV, 1970, págs. 23-29; P. A. Cebollero, La política lingüístico-social de Puerto Rico, San Juan, Consejo Superior de Enseñanza, 1945.

- La cuestión del purismo en América está relacionada con el problema de la unidad y la fragmentación de la lengua y con posturas nacionalistas. Véanse $R$. Menéndez Pidal, "La unidad del idioma", Mis páginas preferidas. Estudios lingüisticos e históricos, Madrid, Gredos, 1957, págs. 46-83; §. Rosenblat, El castellano de España y el castellano de América. Unidad y diferenciación, Caracas, Instituto de Filología "Andrés Bello", 1962; D. Alonso, "Para evitar la diversificación de nuestra lengua", Presente y futuro de la lengua española, II, Madrid, OFINES, 1964, págs. 259-268; R. Lapesa, "América y la unidad de la lengua española", Revista de Occidente, XII, 1966, págs. 300-320.

7 M. Alvar da noticias sobre programas de enseñanza y acciones políticas en " $\mathrm{Bi}$ lingüismo e integración en Hispanoamérica", Hombre, etnia, estado, Madrid, Gredos, 1986, págs. 37-73; y en "Lengua nacional y sociolingüística. Las constituciones de América", $o p$. cit., págs. 262-337.

8 Véase G. Salvador, Política lingüística y sentido común, Madrid, Istmo, 1992. 


\section{Situaciones lingǘsticas en el mundo hispánico}

En las comunidades lingüísticas primarias se producen distintos tipos de relación entre hablas diferentes o entre las hablas y una norma culta. Esto da lugar a cuatro tipos de situaciones que podrían quedar representadas esquemáticamente como en el cuadro siguiente:
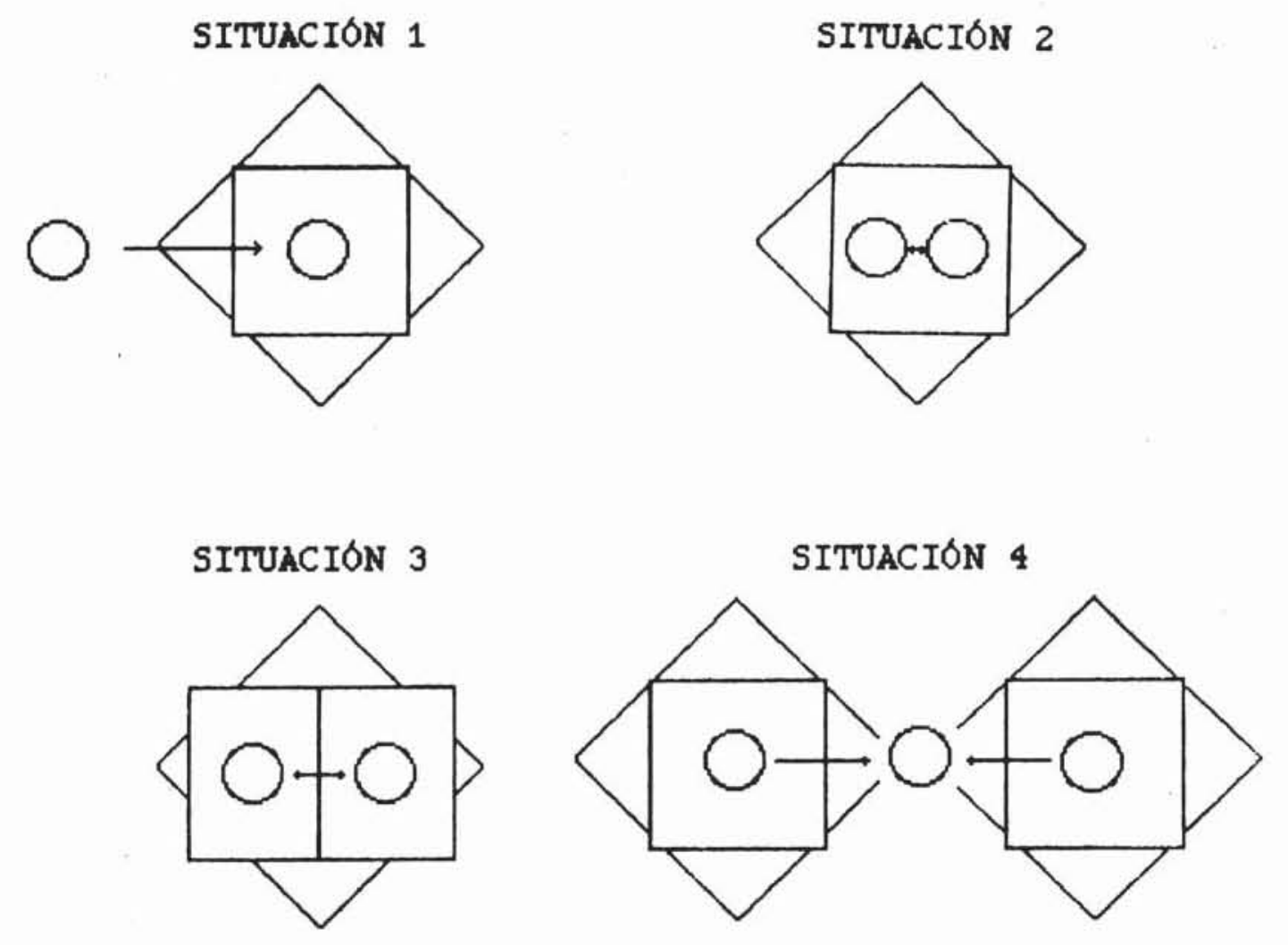

\section{Lengue normative}

$\square$ Norma prestig
Hobla local 
Los esquemas representan situaciones en las que existen hablas locales, marcadas o no ${ }^{9}$, vinculadas a una norma prestigiosa ${ }^{10}$ que, a su vez, se halla dentro del dominio de una lengua regulada a la que hemos denominado "lengua normativa" ".

En el esquema de la Situación 1 se refleja la existencia de un habla local, inserta en una norma prestigiosa, que, a su vez, posee un modelo normativo. Junto a ella puede encontrarse otra habla, vinculada a una lengua diferente, que no cuenta con una referencia prestigiosa ni con un sistema regulado. En esa circunstancia es fácil hallar en la primera elementos de la segunda ${ }^{12}$, aunque la norma ejerce sobre ellos una influencia tal que los hace desaparecer progresivamente.

Las hablas que no conviven con otras variedades, externas o internas, podrian representarse de la misma forma, pero suprimiendo el circulo exterior $^{13}$. Este caso tiene poco interés desde el punto de vista de la planificación. Si lo tendrian, en cambio, aquellas hablas locales desmembradas de su variedad de origen que carecen, en sí mismas, de un punto de referencia prestigioso y normativo (circulo solamente) ${ }^{14}$. En el español de España y en el de América se hallan situaciones lingüísticas como la número 1: piénsese en el contacto del español con hablas indigenas "menores" 15 o en la presencia de

- Aqui no entendemos "habla" en el sentido de estructura de rasgos poco diferenciados limitada a una pequeña circunscripción geográfica (M. Alvar, "Hacia los conceptos de lengua, dialecto y hablas", La lengua como libertad, Madrid, Ediciones Cultura Hispánica, 1982, pág. 65), sino como parole, lengua actualizada tal y como aparece en un lugar determinado.

10 Este concepto viene a coincidir con el de "norma culta", utilizada por los hablantes más prestigiosos de una comunidad $y$, por lo general, en registros cuidados. Puede darse el caso de que exista una norma de prestigio en una lengua que no cuenta con una tradición escrita.

11 El concepto de "lengua normativa" hace referencia a la lengua regulada en las gramáticas, especialmente la de la Academia, y a las normas seguidas en la lengua escrita.

12 Normalmente se trata de elementos que han sobrevivido dentro de hablas locales (seguimos ahora la definición de Alvar) que pertenecieron a una lengua desaparecida como tal. En muchos casos esas unidades son vestigios que sólo se encuentran dentro de otra lengua.

13 El ejemplo más claro, dentro del ámbito hispánico, sería el de las hablas castellanas, que poseen una norma prestigiosa (el castellano) y que han servido de base para gran parte de las prescripciones académicas.

14 Esto ocurre, dentro de la Peninsula Ibérica, con los bables de Asturias o con las fablas del Pirineo aragonés. Un caso de características semejantes, mutatis mutandis, sería el de las hablas canarias transplantadas a algunos territorios norteamericanos (p. e., los habitantes de los brulis en Luisiana): durante decenios han vivido aisladas de su norma de origen, de otras normas hispánicas y de la lengua normativa. (Véase $\mathrm{S}$. Armistead, "Tres dialectos españoles de Luisiana", Lingǘística Española Actwal, XIII, 1991, págs. 279-301.)

15 Los ejemplos se multiplican, por ejemplo, en México. Véase L. Manrique Castañeda, "Pasado y presente de las lenguas indigenas de México", en V. Demonte y 
elementos indigenas dentro de hablas españolas, elementos que ya no tienen un punto de referencia prestigioso, que son vestigios de un sistema que en numerosas ocasiones ha dejado de existir (p. e., lenguas del Caribe) y que están sometidos a un proceso secular de sustitución por unidades de procedencia hispánica ${ }^{16}$. Pensemos también, para el español de España, en la existencia de elementos léxicos de origen leonés dentro de las hablas castellanas del noroeste peninsular ${ }^{17}$.

El esquema de la Situación 2 representa la relación entre dos hablas locales vinculadas a una misma norma de prestigio y a una misma lengua. En este caso se producen influencias de la norma sobre ambas hablas y, a menudo, de una variedad (generalmente la más cercana a la norma) sobre la otra. Esto puede observarse al estudiar el habla toledana actual, que, en determinados registros, acusa el influjo del modelo norteño y de la norma culta ${ }^{18}$. Igualmente, la penetración de un habla (más prestigiosa) en otra se observa en los hablantes que emigran desde las zonas rurales a la ciudad ${ }^{19}$. En América encontramos situaciones semejantes: por ejemplo, la relación

B. Garza (eds.), Estudios de lingüistica de España y México, México, UNAM-El Colegio de México, 1990, págs. 387-420.

16 La sustitución de elementos indigenas por españoles ya fue comentada por Armas y Céspedes en el siglo pasado. (Véase Oríjenes del lenguaje criollo, 2. ${ }^{\mathrm{a}}$ ed., La Habana, 1882.) Más recientemente, J. M. Lope Blanch ha señalado que el número de voces indigenas vivas en las provincias, en el habla campesina, es superior al de indigenismos usuales en las ciudades (Léxico indigena en el español de México, 2 . $^{\mathrm{a}}$ ed., México, El Colegio de México, 1979). Las generaciones jóvenes, sobre todo urbanas, muestran claramente un abandono de las unidades léxicas pertenecientes al mundo rural y a un modo de vida que está siendo sustituido por otro más industrial y moderno. (Véase H. López Morales, "Desgaste léxico en el español de Puerto Rico. El proyecto Malaret", Investigaciones léxicas sobre el español antillano, Santiago, PUCMM, 1991, págs. 169-196; J. M. Lope Blanch, "Indigenismos americanos en la norma lingüística culta de México", Investigaciones sobre dialectología mexicana, 2. ${ }^{\text {a }}$ ed., México, UNAM, 1990, págs. 147-160. Por otro lado, se ha comprobado que la mayor parte de los indigenismos que tienen vitalidad en determinadas zonas americanas son los que han pasado ya a la lengua general.

17 Véase J. Borrego, Sociolingüística rural. Investigación en Villadepera de Sayago, Salamanca, Universidad de Salamanca, 1981; J. C. González Ferrero, Estratificación sociolingüistica de una comunidad semiurbana: Toro (Zamora), Salamanca, Universidad de Salamanca, 1991.

18 Véase P. García Mouton y F. Moreno Fernández, “Atlas Lingüistico (y etnográfico) de Castilla-La Mancha. Materiales de Ciudad Real y Toledo” (en prensa). I. Molina Martos, Estudio sociolingüistico de la ciudad de Toledo, Madrid, 1991. Tesis doctoral inédita.

10 Véanse R. Caravedo, Sociolingüistica del español de Lima, Lima, Fondo editorial de la Pontificia Universidad Católica del Perú, 1990, págs. 17-37; P. Martín Butragueño, Desarrollos sociolingüísticos en una comunidad de habla, Madrid, 1991. Tesis doctoral inédita. 
existente entre el habla rural y el habla urbana en Puerto Rico ${ }^{20}$ (la primera se deja influir en ciertos contextos por la segunda) ${ }^{21}$.

En la Situación número 3 se da cuenta de la existencia de dos hablas locales, cada una de ellas con su propia norma culta, aunque pertenecientes a la misma lengua. Es lógico en tales circunstancias, que una de estas hablas acuse la presión de la otra norma culta, presión que se ve favorecida por el hecho de tener detrás una misma referencia prescriptiva. Es el caso de la relación del habla y la norma de algunas comunidades americanas ( $y$ españolas), respecto del habla y la norma castellanas ${ }^{22}$. Todo ello está también ligado a la actitud positiva que muchos hablantes hispanoamericanos demuestran hacia las variedades lingüisticas de España ${ }^{23}$.

Finalmente, el esquema de la cuarta situación es similar al de la tercera, pero en este caso cada norma pertenece a una lengua diferente. Las interrelaciones entre dos sistemas distintos se dan frecuentemente en los lugares donde entran en contacto: las zonas fronterizas. Aqui puede observarse la influencia sobre un habla de otra habla, otra norma y otra lengua diferentes. En tales situaciones suelen aparecer variedades lingüisticas mezcladas que tienen como base una $\mathrm{u}$ otra lengua. Es lo que ocurre en la frontera catalanoaragonesa (chapurriau) ${ }^{24}$ o en los limites de Uruguay y Brasil (fronterizo) ${ }^{25}$.

Todas estas situaciones presentan unas peculiaridades que serian dignas de atención a la hora de realizar una planificación lingüística.

20 Véanse T. Navarro Tomás, El español en Puerto Rico, Río Piedras, Universidad de Puerto Rico, 1948, págs. 229 y sigs.

21 Por otra parte, el habla rural suele compartir muchos rasgos con el habla de los niveles socio-culturales más bajos de las ciudades. En estos casos, el abandono de los rasgos poco prestigiosos por parte de las generaciones más jóvenes está bastante generalizado. Véase O. Alba, Variación fonética y diversidad social en el español dominicano de Santiago, Santiago, PUCMM, 1990, págs. 218-224; H. López Morales, "Velarización de /RR/ en el español de Puerto Rico: índices de actitud y de creencias", Dialectología y sociolingüistica. Temas puertorriqueños, Madrid, Hispanova de ediciones, 1979, págs. 107-130.

23 En Sevilla, por ejemplo, el seseo (rasgo que separa claramente la norma sevillana y la castellana) tiene un indice de aceptación, entre los hablantes cultos, más bajo que el de otros fenómenos teóricamente menos diferenciadores, como la aspiración de $s$. Esto se debe a la presión de la norma castellana. Véase V. Lamiquiz y P. Carbonero, Perfil sociolingüistico del sevillano culto, Sevilla, Universidad de Sevilla, 1987, págs. 29-48.

23 Véase M. Alvar, Hombre, etnia, estado. Actitudes lingüisticas en Hispanoamérica, op. cit., págs. 158-162, 189-191. También J. M. Lope Blanch, “El concepto de prestigio y la norma lingüística del espafiol". Anuario de Letras, X, 1972, págs. 29-46.

24 Véase M. Alvar, "Un problema de lenguas en contacto: la frontera catalanoaragonesa", Teoría lingiüistica de las regiones, Barcelona, Planeta, 1975, págs. 47-62.

${ }_{25}$ Véase H. Lónez Morales, Sociolingüistica, Madrid, Gredos, 1989, págs. 153-162. También J. P. Rona, El dialecto "fronterizo" del norte de Uruguay, Montevideo, Adolfo Linardi, 1965; A. Elizaincín, Dialectos en contacto. Español y portugués en España y América, Montevideo, Arca, 1992. 
En las comunidades bilingües, las circunstancias socio-espaciales son diferentes. En ellas se da la superposición de dos lenguas. Algunas veces, cada una posee una norma prestigiosa y disfruta de un punto de referencia normativo (situación 5); otras, una de las hablas posee su norma prestigiosa vinculada a una lengua normativa, pero la otra puede carecer de esta última (situación 6). Una situación similar a la descrita en el número 5 es la que se da en comunidades hispanas de Estados Unidos ${ }^{26}$. La número 6 se da en las comunidades en las que el español convive con alguna lengua indigena de cierta importancia ${ }^{27}$. En ambas es usual la aparición de variedades de compromiso consecuencia del contacto lingüístico (por ejemplo, el llamado "espanglish" de las comunidades puertorriqueñas de Nueva York o la "media lengua" en el Ecuador, mezcla de quechua y español) ${ }^{28}$.

\section{SITUACIOK 5}

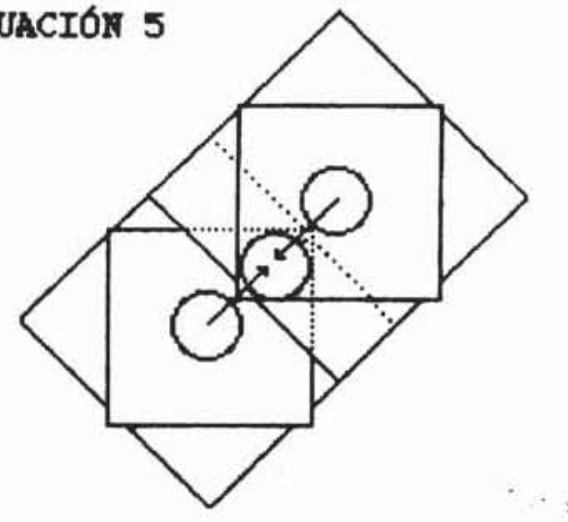

\section{SITUACIÓN 6}

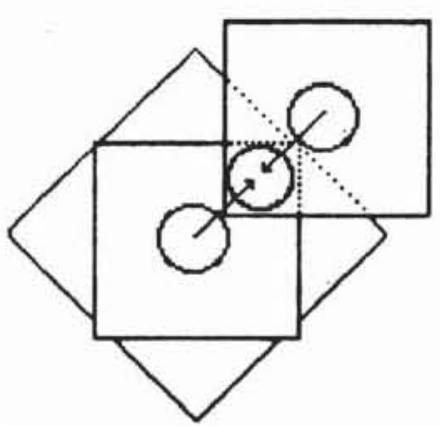

Las situaciones aquí descritas hacen ver que cualquier planificación de la lengua española tendria que tratar los siguientes aspectos:

1. El español ante sus variedades dialectales internas.

2. El español ante las lenguas indigenas (minoritarias y de gran difusión).

26 Véase J. Amastae y L. Elías-Olivares, Spanish in the United States, Nueva York, Cambridge University Press, 1982; S. Poplack, "Lenguas en contacto", en H. López Morales (coord.), Introducción a la lingüistica actual, Madrid, Playor, 1983, págs. 183-207.

27 Pensamos en lenguas como el quechua, el guaraní o el náhuatl. Es posible que muchos de sus hablantes no sean "cultos" y que no cuenten con tradición literaria importante, pero ello no impide necesariamente que una variedad pueda disfrutar de prestigio entre sus usuarios. Véase G. de Granada, "Actitudes sociolingüísticas en el Paraguay", Boletin de Filología de la Universidad de Chile, XXXI, 1980-1981, págs. 787-805.

28 P. Muysken, "La mezcla de quechua y castellano: el caso de la 'media lengua' en el Ecuador", Lexis, III, 1979, págs. 41-56. 
3. El español ante las variedades mixtas.

4. El español en paises de lengua oficial diferente.

\section{La finalidad de UNA PLANificación dE LA LENGUA ESPAÑola}

El español merece una planificación lingüistica que aporte soluciones a los muchos problemas que se presentan a sus hablantes (y a la propia lengua) en todo el mundo. Aunque son necesarias unas lineas de conducta comunes para el conjunto del territorio hispánico, cada pais requiere una planificación adecuada a sus caracteristicas.

Ya hemos señalado en otro lugar ${ }^{29}$ que cualquier proceso de planificación debe afrontar una doble tarea: la planificación del corpus lingüístico y la planificación de su status social ${ }^{30}$. Desde el punto de vista del corpus, el criterio de la "corrección" suele orientar el uso lingüístico, porque las comunidades necesitan y exigen una norma "correcta" que seguir ${ }^{31}$. Las Academias pretenden satisfacer esta necesidad en los paises de habla hispana, si bien su fruto ha tenido un alcance bastante restringido.

Los paises americanos de habla española han conocido intentos de planificación del corpus y decisiones de defender la pureza del español frente al empuje de otras lenguas de cultura. Por otro lado, mediante determinadas acciones de política lingüistica, se ha reconocido la oficialidad de unas lenguas o de otras, aunque a menudo no se haya ido mucho más allá. En repetidas ocasiones se han puesto sobre la mesa los problemas que plantean las variedades internas del español, especialmente en lo que concierne a la unidad de la lengua o a la defensa de un nacionalismo lingüistico ${ }^{32}$, sin embargo rara vez ha tenido todo ello un reflejo en la práctica. En cuanto al status

29 Véase nota 1

30 Sobre el proceso de "planificación lingüística", véanse los siguientes trabajos: $V$. Tauli, "El planeamiento del lenguaje", en $O$. Uribe Villegas (ed.), La sociolingüistica actual, México, UNAM, 1974, págs. 246-267; J. Rubin y B. Jernudd (eds.), Can Language Be Planned?. Honolulu, East-West Center and University of Hawaii Press, 1971; J. Fishman (ed.), Advances in Language Planning, La Haya, Mouton, 1974; J. Cobarrubias y J. Fishman (eds.), Progress in Language Planning, La Haya, Mouton, 1983. Hacemos una breve presentación del desarrollo de esta materia en "Planificación lingüística y dialectología", art. cit.

31 En este sentido, una de las iniciativas más importantes en Hispanoamérica fue la Gramática de la lengua castellana destinada al uso de los americanos de A. Bello (Santiago de Chile, 1847).

32 Véase, por ejemplo, M. I. Blanco de Margo, "El nacionalismo y las actitudes hacia la lengua en la Argentina", Anuario de linguiistica hispánica, VI, 1990, págs. 6586. También R. C. Troike, "Problems of Language Planning for Spanish in the United States”, Word, XXXIII, 1982, págs. 69-80. 
de nuestra lengua en comunidades no hispánicas, apenas ha inquietado a los especialistas, si exceptuamos la pura descripción sociolingüística ${ }^{33}$.

Para planificar el español seria necesario tener en cuenta las situaciones en que esta lengua convive con otras y las diferentes circunstancias lingüísticas que concurren en el territorio monolingüe y que hemos representado en nuestros esquemas.

Las situaciones lingüísticas del mundo hispánico encierran unos problemas complicados e interesantes: cómo tratar los préstamos aportados por otras hablas o lenguas, qué variedad del español enseñar y en qué variedad enseñarla, qué variedades deben usarse en los medios de comunicación social, cómo solucionar las dificultades que surgen en la relación entre lengua escrita y lengua hablada, qué status deberian tener las lenguas minoritarias y las variedades mixtas.

En nuestra opinión, los objetivos generales de una planificación del español podrian buscar lo siguiente:

a) favorecer la unidad y el enriquecimiento de la lengua;

b) garantizar el derecho a comunicarse en esa lengua en situaciones públicas;

c) proteger el derecho a hacer un uso correcto y prestigioso de la lengua.

Estos fines afectarian tanto a los territorios monolingües como a los bilingües. Los objetivos específicos serian asunto de cada nación hispanohablante.

Una planificación de la lengua española en los territorios bilingües deberia atender al status que habría de ocupar respecto de las otras lenguas y a su uso en la enseñanza, la administración, las instituciones juridicas o los medios de comunicación social; en otras palabras, tendria que garantizar el derecho de los ciudadanos a comunicarse en esa lengua. Claro está que la política lingüistica tendría que ir en consonancia con los fines planificados y, en nuestra opinión, procurar un beneficio para el hablante -el individuo-, por más que queden subordinados otros intereses sociales, ideológicos o políticos.

En cuanto a las situaciones monolingües, una planificación tendría que ser capaz de proporcionar una respuesta a la siguiente pregunta: ¿qué variedad del español hay que enseñar y cómo hacerlo? La falta de una guía clara obliga a muchos maestros y profesores a buscar sus propias respues-

3s Véase E. Alvarado de Ricord, "Condiciones sociales del español estadounidense", Boletín de la Academia Norteamericana de la Lengua Española, II-III, 1977-1978, págs. 41-48. 
$\operatorname{tas}^{34}$. La falta de orientaciones generales y el desconocimiento de la realidad lingüística del español (dialectal y sociolingüística) hacen que esas respuestas no sean siempre las más acertadas. El trabajo de la escuela ha de recibir atención, porque alli se reflejan las caracteristicas de la sociedad, los deseos y las necesidades sociales ${ }^{35}$.

Dentro de una situación como la número 1 , un maestro puede sentirse en la obligación de hacer que sus alumnos sustituyan indiscriminadamente un léxico de origen indigena por otro castellano ${ }^{36}$. También podria ser que el maestro, llevado de un sentimiento "autóctono", intentara generalizar el uso de formas indígenas alli donde no tienen ningún tipo de aval histórico. Las palabras de Vidal de Battini son de una gran sensatez:

Para que el maestro pueda ejercer con eficacia su acción docente, es necesario que conozca bien las manifestaciones del habla popular de su región, y que sepa a qué se debe cada una de sus peculiaridades; que no las juzgue simple producto de la ignorancia, de la arbitrariedad o del disparate, sino producto muchas veces, de una tradición secular, y otras, de la acción lingüistica (tendencias fonéticas o analógicas), que actúan sobre la lengua del lugar y también sobre grandes áreas del mundo hispano ${ }^{37}$.

Sabido es que el esfuerzo de la Academia por recoger voces regionales ha sido generoso, pero irregular a lo largo de su historia ${ }^{38}$. Hoy disponemos de atlas lingüísticos que dan fe de unos usos que bien podrian figurar en las obras lexicográficas ${ }^{39} \mathrm{y}$ en un tiempo dispondremos de un Atlas Lingüístico de Hispanoamérica que dará por primera vez una imagen de conjunto ${ }^{40}$.

34 No han sido frecuentes esfuerzos como el que hizo B. E. Vidal de Battini para apoyar a los maestros de las escuelas primarias (El español de la Argentina, Buenos Aires, Consejo Nacional de Educación, 1964) o como el de A. Bello para orientar a padres y profesores ("Advertencias sobre el uso de la lengua castellana", El Araucano. 1833 y 1834.

36 J. Fishman, "The Social Science Perspective", Bilingual Education: Current Perspectives, vol. 1, Arlington, Center for Applied Linguistics, 1977, pág. 4.

*Véase L. E. López, "El bilingüismo de los unos y de los otros: diglosia y conflicto lingüfstico en el Perú", en E. Ballón Aguirre y R. Cerrón-Palomino (eds.), Diglosia linguo-literaria y educación en el Perú. Homenaje a Alberto Escobar, Lima, CONCYTEC, 1990, págs. 91-124.

s7 $O$ p. cit., pág. 16.

38 Véase M. Alvar, "Atlas lingüísticos y diccionarios", en Estudios de geografía lingüística, Madrid, Paraninfo, 1991, págs. 50-51. También, F. Lázaro Carreter, "El primer diccionario de la Academia", en Estudios de lingüística, Barcelona, Crítica, 1980, págs. 83-148.

${ }^{30}$ Véase M. Alvar, "Atlas lingüísticos y diccionarios", art. cit. También, G. Salvador, "Lexicografía y geografía lingüística", en Semántica y lexicología del español, Madrid, Paraninfo, 1984, págs. 138-144.

40 Véase M. Alvar, "Proyecto de un Atlas Lingüístico de Hispanoamérica", Estudios de geografía lingüística, Madrid, Paraninfo, 1991, págs. 439-456. 
Unas situaciones como las representadas en los esquemas 2 y 3 plantean el problema de qué habla enseñar, cómo enseñarla y en qué variedad enseñarla.

Nuestra opinión es que ante una variedad que no coincide en todos sus rasgos con los marcados por las normas generales de la lengua existen dos opciones lógicas (opciones que los centros de enseñanza podrian orientar): si la modalidad no posee una norma culta propia, la escuela debería enseñar la variedad más prestigiosa del ámbito en el que se mueven los hablantes ${ }^{41} \mathrm{y}$ encauzar los usos locales hacia unos registros muy limitados; si su habla tiene una norma culta propia y una referencia de prestigio (como es el caso de México, San Juan de Puerto Rico, etc.) o no está suficientemente diferenciada de ella, parece clara la necesidad de que se haga ver a los alumnos cuáles son sus rasgos cultos, para avalar su uso, y cuáles no lo son, para restringirlos a ciertos contextos. Ello no tendria que ir en detrimento de la enseñanza de las características "generales" del español, con el fin de que puedan ser utilizadas cuando la situación y el contexto se lo exijan al hablante y de favorecer la unidad del español ${ }^{42}$. Manuel Alvar señaló en 1979 que la corrección idiomática no es un deber sino un derecho al que deben acceder los ciudadanos libres ${ }^{43}$.

Al enseñar, el profesor utilizará una norma culta de la lengua, pero sería aconsejable respetar la norma culta de los propios alumnos, propiciando su uso en detrimento de los rasgos populares en ciertos registros. Esta solución exige un buen conocimiento de la norma culta del español en sus diferentes regiones, si bien para conseguirlo, han de hacerse aún numerosas investigaciones ${ }^{4}$. Por aqui podría producirse un acercamiento entre lengua hablada y lengua escrita, que sería necesario antes de propugnar cualquier tipo de reforma de la ortografía española.

Sin embargo, actualmente la escuela no es el medio más eficaz de divulgar una norma y conferirle un status. Una parte importantísima de la población no puede ser escolarizada o lo es insuficientemente. Ahora bien, donde no alcanza la escuela pueden llegar los medios de comunicación social. Por eso es importante que la variedad lingüística que alli se utiliza haya sido, al menos, objeto de reflexión por parte de los comunicadores.

Los medios de comunicación social pueden ser un instrumento eficaz

41 La que más beneficios y ventajas sociales pueda aportar a los individuos.

42 Por ejemplo, dar a conocer el uso de los pronombres tú y vosotros, con los correspondientes paradigmas verbales.

4s Lo mismo ha señalado Alvar para la ortografía ("Fonética, fonología y ortografía", La lengua como libertad, Madrid, Ediciones Cultura Hispánica, 1982, pág. 239.

4 Los estudios sobre la norma culta de las principales ciudades de España e Hispanoamérica están comenzando a dar resultados. Véase J. M. Lope Blanch, El estudio del español hablado culto. Historia de un proyecto, México, UNAM, 1986. 
para la planificación lingüistica. De momento, están consiguiendo que los hablantes de unas variedades de español conozcan otras muy lejanas y diferentes, lo que afecta a sus actitudes lingüísticas ${ }^{45}$, y se están convirtiendo en paradigma indiscutible de buen hablar, de prestigio. Si conociéramos bien la lengua de la radio y la televisión, sabriamos qué dirección pueden tomar, en plazos muy breves, algunos cambios lingüisticos y podriamos orientarlos. Los medios de comunicación pueden ser decisivos para el cumplimiento del objetivo general que hemos antepuesto a los demás: hacer al español más rico $\mathrm{y}$ potenciar su unidad ${ }^{46}$.

En una situación como la representada en el cuarto esquema, la planificación lingüística podría atender a la posibilidad de una educación bilingüe capaz de determinar el status de cada una de las lenguas y de relegar el uso de la lengua mixta a unos pocos contextos situacionales.

Los esquemas 5 y 6 presentan problemas diferentes, aunque coincidan en algunos aspectos básicos con lo ya señalado. Dentro de las comunidades bilingües, sería conveniente que la planificación de la lengua española estuviera coordinada con una planificación de la otra lengua. En la situación 5 podría procurarse un aumento del número de hablantes, pero no creemos que ése deba ser uno de los objetivos fundamentales. El aumento de hablantes en un país como los Estados Unidos de América es engañoso, porque no supone un crecimiento del prestigio de su variedad lingüistica. Una situación así lleva indefectiblemente a la asimilación lingüistica ${ }^{47}$. La planificación del español tendria que incidir en la difusión de una norma culta de la lengua. Si luego los hablantes acaban asimilándose a otra lengua es asunto que afecta sólo a los intereses socio-económicos del individuo y del país en que desarrolla su actividad.

La clave de lo que pueda ocurrir en Estados Unidos en el futuro estará en la política lingüística que se realice por parte del gobierno norteamericano, pero ello no exime de toda responsabilidad a la política de los países de lengua española, de forma muy especial la política de México, de Puerto Rico, de Cuba, de Centroamérica y de España. Pero, si los hombres no encauzan el desarrollo de la lengua, la lengua se seguirá autoplanificando.

Está demostrado que la política lingüistica estadounidense es eficaz para

45 Está siendo importante la emisión de telenovelas realizadas en algunos países americanos (Venezuela, México) y emitidas en diversos países hispanohablantes, incluido España.

46 Ya hay un proyecto en marcha con esta intención: DIES-RTV ("Difusión del español en radio y televisión"). Véase R. Avila, "El lenguaje de la radio y la televisión: primeras noticias", Segundo encuentro de lingüistas y filólogos de España y Mérico (en prensa).

47 Véase C. Veltman, The Retention of Minority Languages in the United States, Washington, D. C., National Center for Education Statistics, 1980. 
sus fines, porque durante decenios ha llevado a la asimilación cultural de los extranjeros. Hoy ese proceso sufre una acción que interrumpe lo que ha sido una evolución constante. Nos referimos a la entrada masiva de hispanohablantes monolingües e incultos. Si la inmigración continúa con las dimensiones y la intensidad actuales, se producirá un efecto desconocido hasta ahora en Estados Unidos. En su política de inmigración y educativa está el poder para devolver el fenómeno a los terrenos de la asimilación. En caso contrario, el Gobierno norteamericano tendría que hacer una política en la que el mundo hispánico ocupara un lugar importante. Pero insistimos en que no debe echarse en saco roto la trascendencia de una buena política lingüística por parte de los países de habla española, porque pueden conseguir que la cultura hispánica en Norteamérica sea digna de consideración desde una perspectiva cualitativa y no sólo cuantitativa, como ocurre en este momento. Los hablantes tienen derecho a hacer un uso correcto de su propia lengua y ese uso se aprende.

Las situaciones incluidas en el esquema 6 requeririan tanto una planificación del español como de la otra lengua. Excepto lo que se refiere a unos objetivos generales como los que antes hemos expuesto, todo depende del interés de cada nación por sus lenguas indígenas ${ }^{48}$. Si la lengua indigena es de carácter minoritario, parece lógico que la planificación oriente el uso de tal lengua a contextos muy concretos y proporcione a los hablantes indigenas monolingües una enseñanza adecuada de la lengua española. Si, por el contrario, la lengua indigena está bien asentada social y demográficamente, se hace necesaria una politica de bilingüismo en la que se respeten los derechos del individuo en lo que concierne al uso de la lengua española.

\section{Conclusiones}

Una planificación del espafiul es, hoy por hoy, difícil de realizar, porque para planificar bien hay que conocer previamente cuáles y cómo son las situaciones lingüísticas en todos los territorios en los que se habla una lengua $y$ las actitudes de los hablantes.

De los sucintos comentarios que hemos presentado, podemos entresacar

48 Ahora bien, el español se ve involucrado cuando se ponen en marcha planes de educación bilingüe para los indígenas. En ellos se persiguen diversos objetivos (educación bilingüe de transición; educación bilingüe de mantenimiento). Véase G. Ruiz de Bravo Ahuja, "El proceso del bilingüismo en contexto multiétnico (Educación escolarizada en México)", en B. Garza y P. Levy (eds.), Homenaje a Jorga A. Suáres. Lingüística indoamericana e hispánica, México, El Colegio de México, 1990, págs. 459-475; A. Najarro Arriola, "Un nuevo enfoque para la educación bilingüe en Guatemala", Boletín de Lingüistica. Universidad Rafael Landivar, 21-23, mayo-octubre (1990), págs. 2-8. 
algunas conclusiones. Ante todo, sería conveniente que una planificación de la lengua española atendiera a sus relaciones con las lenguas con que convive $y$ a las que establecen sus variedades internas, con el fin de favorecer la unidad y el enriquecimiento de la lengua, garantizar el derecho de los ciudadanos a comunicarse en ella $y$ proteger el derecho a hacer un uso correcto $y$ prestigioso de la lengua. Cada nación hispanohablante podría buscar unos objetivos específicos, adecuados a su peculiar situación, procurando el beneficio de los hablantes como individuos y subordinando otros intereses socio-políticos o ideológicos. 